\title{
Microaneurysms in the development of diabetic retinopathy (UKPDS 42)
}

\author{
E.M. Kohner ${ }^{1}$, I.M. Stratton ${ }^{2}$, S.J. Aldington ${ }^{3}$, R. C. Turner ${ }^{2}$, D. R. Matthews ${ }^{2}$ for the UK Prospective Diabetes \\ Study (UKPDS) Group \\ ${ }^{1}$ Department of Medicine St. Thomas' Hospital, London, UK \\ ${ }^{2}$ Diabetes Research Laboratories, Radcliffe Infirmary, Woodstock Road, Oxford, UK \\ ${ }^{3}$ Retinopathy Grading Centre, Imperial College School of Medicine, London, UK
}

\section{Abstract}

Aims/hypothesis. To determine whether microaneurysms, in the absence of other lesions, have a predictive role in the progression of diabetic retinopathy in Type II (non-insulin-dependent) diabetes mellitus.

Methods. Retinal photographs taken at diagnosis in patients participating in the United Kingdom Prospective Diabetes Study, and thereafter at 3 yearly intervals, were assessed using a modified Early Treatment of Diabetic Retinopathy grading system for lesions of diabetic retinopathy and end points of vitreous haemorrhage and photocoagulation. The number of microaneurysms in each eye was recorded.

Results. The changes between diagnosis and later photographs were analysed in 2424 patients at 6 years, 1236 at 9 years and 414 at 12 years. Of the 2424 patients studied in the 6 year cohort 1809 had ei- ther no retinopathy or microaneurysms only at entry. In these patients the presence of microaneurysms alone and also the number of microaneurysms had a high predictive value for worsening retinopathy at 3 , 6,9 , and 12 years after entry into the study (e.g. at 6 years $\chi^{2}$ for trend $=75$ on $1 \mathrm{df}, p<0.001$ ). The predictive value of the presence or absence of microaneurysms and their number at 3 years from diagnosis and subsequent worsening retinopathy was similar to that at entry.

Conclusion/interpretation. Microaneurysms are important lesions of diabetic retinopathy and even one or two microaneurysms in an eye should not be regarded as unimportant. [Diabetologia (1999) 42: 1107-1112]

Keywords Diabetic retinopathy, microaneurysms, UKPDS, Type II diabetes, diabetes, complications.
Microaneurysms (MA) are the hallmark of diabetic retinopathy, and are the earliest clinically recognisable features of the condition. They have, however, been found in patients without diabetes [1] and this raises the question whether the presence of a few MAs, in the absence of any other retinal lesion, are of any importance in diabetic patients. This is further emphasised by the fact that although MAs are most

Received: 10 November 1998 and in revised form: 26 February 1999

Corresponding author: E.M. Kohner, Department of Medicine, St. Thomas' Hospital, Lambeth Palace Rd., London SE1 $7 \mathrm{EH}, \mathrm{UK}$

Abbreviations: MA, Microaneurysms; UKPDS, United Kingdom Prospective Diabetes Study. commonly seen in the perifoveal area, they are only rarely the cause of visual impairment.

To determine the importance of MAs and particularly whether they have a predictive value for the progression of diabetic retinopathy we examined the photographs of patients in the United Kingdom Prospective Diabetes Study (UKPDS), a large multicentre randomised controlled clinical study of different treatments in newly diagnosed Type II diabetic patients. This paper presents the result of that study.

\section{Subjects and methods}

Details of the UKPDS, patient recruitment and randomisation have been reported [2]. In brief, patients in whom Type II (non-insulin-dependent) diabetes mellitus had been newly di- 
Table 1. Summarised 'Modified ETDRS Final' retinopathy levels

\begin{tabular}{|c|c|c|}
\hline Level & Severity & Definition \\
\hline 10 & DR absent & All DR features absent \\
\hline 20 & MA only & $\begin{array}{l}\text { Microaneurysm(s) only, other } \\
\text { features absent }\end{array}$ \\
\hline 35 & Mild NPDR & $\begin{array}{l}\text { MA, + retinal haemorrha- } \\
\text { ge(s) and/or hard exudates, } \\
\text { and/or cotton wool spots }\end{array}$ \\
\hline 43 & Moderate NPDR & $\begin{array}{l}\text { Lesions as above }+ \text { either ex- } \\
\text { tensive or severe HMA or } \\
\text { IRMA present }\end{array}$ \\
\hline 47 & $\begin{array}{l}\text { Moderately } \\
\text { severe NPDR }\end{array}$ & $\begin{array}{l}\text { Lesions of } 35 \text { with either ex- } \\
\text { tensive and severe HMA with } \\
\text { IRMA or venous beading }\end{array}$ \\
\hline 53 & Severe NPDR & $\begin{array}{l}\text { Very severe HMA, } \pm \text { IRMA } \\
\pm \text { VB }\end{array}$ \\
\hline $61,65,71,75$ & PDR & $\begin{array}{l}\text { NVD and/or NVE without or } \\
\text { with complications }\end{array}$ \\
\hline 81 & Advanced PDR & $\begin{array}{l}\text { Retina obscured by VH or } \\
\text { PRH }\end{array}$ \\
\hline 99 & Cannot grade & \\
\hline
\end{tabular}

Abbreviations: DR = diabetic retinopathy, NPDR = Non-proliferative diabetic retinopathy, $\mathrm{PDR}=$ Proliferative diabetic retinopathy, $\mathrm{MA}=$ Microaneurysm, $\mathrm{HMA}=$ haemorrhages and microaneurysms, IRMA = intra retinal microvascular abnormalities, NVD = new vessels on the disc, NVE = new vessels elswhere, $\mathrm{VH}=$ vitreous haemorrhage, $\mathrm{PRH}=$ pre-retinal haemorrhage, $\mathrm{VB}=$ Venous beading

agnosed were treated for 3 months with diet only. If after that time they were still hyperglycaemic, but symptom free, they were randomly allocated to remain on diet only or be treated with an oral hypoglycaemic agent or insulin [3]. Patients were seen at 3 monthly intervals in the diabetic clinic, and had a full medical examination at entry and yearly thereafter, including visual acuity determination and retinal examination by ophthalmoscopy. At 3 yearly intervals retinal photographs were taken of four standard stereo-pairs of each eye and assessed as described previously [4].

Assessment of retinal photographs. Retinal photographs were masked for all patient identifying details and assigned with a unique identification number. Photographs were centrally assessed by two independent experienced readers for quality and adherence to the photographic protocol as well as the presence of any diabetic retinal lesions. When such lesions were present, the photographs received a detailed assessment involving the classification of the retinal lesions against Airlie House standard photographs [5] again carried out in duplicate.
A computer algorithm then assigned a retinopathy level for each eye according to a modified Early Treatment of Diabetic Retinopathy grading system [6]. A simplified summary is seen in Table 1.

During the detailed assessment stage, graders carried out a manual count of the total number of MAs present in each eye. The number of MAs was recorded for each eye as absent (0); present, numbering 1, 2, 3, 4, or 5 in the eye; present, numbering 6-10 in the eye; or present in numbers greater than 10 . As there was overlap between the four fields, this was taken into account during the counting exercise. Independent adjudication of differences was applied throughout all stages of assessment.

Statistical analysis. Mantel-Haenszel chi-squared statistics were used for determining the trend in retinopathy severity relating to the number of MAs present at entry and to that at subsequent 3-year intervals. All data were analysed using SAS (SAS Institute, Carey, N. C., USA).

\section{Results}

There were 5102 patients who entered the UKPDS. Of these 3569 had retinal photographs at entry. There were 2424 subjects who had photographs both at entry (baseline) and 6 years; 1809 of these had either no retinopathy or MAs only at entry. A cohort of 1236 of these were also studied at baseline and 9 years and 414 at baseline and 12 years.

There was no statistically significant relation between the number of MAs at entry and the clinical and biochemical variables measured, including sex, race, smoking, body mass index, systolic blood pressure, fasting plasma glucose, $\mathrm{HbA}_{1 \mathrm{c}}$, fasting plasma insulin, insulin sensitivity, beta-cell function, HDL or LDL cholesterol or triglyceride [2].

Disappearance rate of microaneurysms. Table 2 shows the disappearance rate of MAs at 6, 9 and 12 years. This indicates that MAs were most likely to disappear if there was only one present, when about $50 \%$ disappeared at each time interval. In contrast only a third of subjects was there a total disappearance when there were two or three present at entry, and less than one in six when there were five or more present.

Table 3 shows the relation between those in whom MAs disappeared by 3 years and those who had no

Table 2. Disappearance rate of microaneurysms

\begin{tabular}{|c|c|c|c|c|c|c|c|c|}
\hline $\begin{array}{l}\text { Number of } \\
\text { microaneurysms } \\
\text { at entry }\end{array}$ & $\begin{array}{l}\text { 3-year } \\
\text { cohort }\end{array}$ & & $\begin{array}{l}\text { 6-year } \\
\text { cohort }\end{array}$ & & $\begin{array}{l}\text { 9-year } \\
\text { cohort }\end{array}$ & & $\begin{array}{l}\text { 12-year } \\
\text { cohort }\end{array}$ & \\
\hline 1 & $160 / 315$ & $50.8 \%$ & $121 / 255$ & $47.5 \%$ & $86 / 180$ & $47.8 \%$ & $30 / 68$ & $44.1 \%$ \\
\hline 2 & $57 / 153$ & $37.2 \%$ & $42 / 127$ & $33.1 \%$ & $27 / 77$ & $35.1 \%$ & $7 / 21$ & $33.3 \%$ \\
\hline 3 & $24 / 73$ & $32.9 \%$ & $20 / 65$ & $30.8 \%$ & $12 / 48$ & $25.0 \%$ & $4 / 13$ & $30.8 \%$ \\
\hline 4 & $11 / 30$ & $36.7 \%$ & $8 / 23$ & $34.8 \%$ & $4 / 15$ & $26.7 \%$ & $1 / 2$ & $50.0 \%$ \\
\hline 5 & $10 / 44$ & $22.7 \%$ & $6 / 36$ & $16.7 \%$ & $3 / 25$ & $12.0 \%$ & $0 / 7$ & $0 \%$ \\
\hline
\end{tabular}


Table 3. Retinopathy level at 6 years in those without MAs at 3 years

\begin{tabular}{llccc}
\hline $\begin{array}{l}\text { No. of micro- } \\
\begin{array}{l}\text { aneurysms } \\
\text { at entry }\end{array}\end{array}$ & $\begin{array}{l}\text { no retino- } \\
\text { pathy }\end{array}$ & $\begin{array}{l}\text { MA } \\
\text { only }\end{array}$ & $\begin{array}{l}\text { More } \\
\text { severe }\end{array}$ & Total \\
\hline 0 & 600 & 196 & 100 & 896 \\
& 67.0 & 21.9 & 11.1 & \\
1 & 69 & 38 & 16 & 123 \\
& 56.1 & 30.9 & 13.0 & \\
2 & 24 & 11 & 8 & 43 \\
& 55.8 & 25.6 & 18.6 & \\
3 & 11 & 5 & 1 & 17 \\
& 64.7 & 29.4 & 5.9 & \\
4 & 5 & 3 & 1 & 9 \\
& 55.5 & 33.3 & 11.1 & \\
5 or more & 5 & 1 & 2 & 8 \\
& 62.5 & 12.5 & 25.0 & \\
\hline
\end{tabular}

Mantel Haenszel chi-squared for trend $0.936, p=0.333$

Numbers in italics indicate percentage

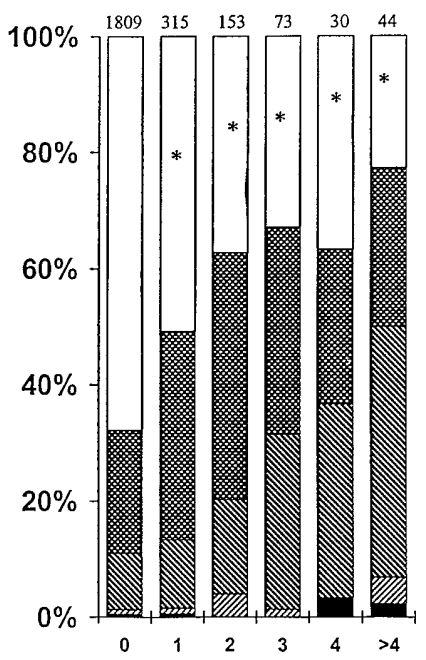

Fig. 1. Retinopathy at 3 years by number of microaneurysms at entry. Number above columns shows total number of eyes in that group. Vertical axis shows per cent of eyes in each category indicated in to the right of the columns. Clear part of column with asterisk shows per cent of eyes in which the microaneurysms have disappeared. *- MA disappeared; $\square$ no retinop-

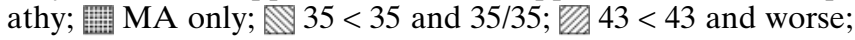

$\square$ photocoagulation or vitreous haemorrhage

MAs at entry and the 6 year retinopathy level. This shows that there is no difference in retinopathy severity at 6 years between those with and those without MAs at 3 years.

Formation of microaneurysms. This study does not allow for determination of the formation rate of new MAs, because only the total number of MAs was counted. The patients, however, who developed, MAs only when they had no retinopathy at a previous visit was approximately $20 \%$ at each 3 year interval; $19.7 \%$ between entry and 3 years; $24.7 \%$ between

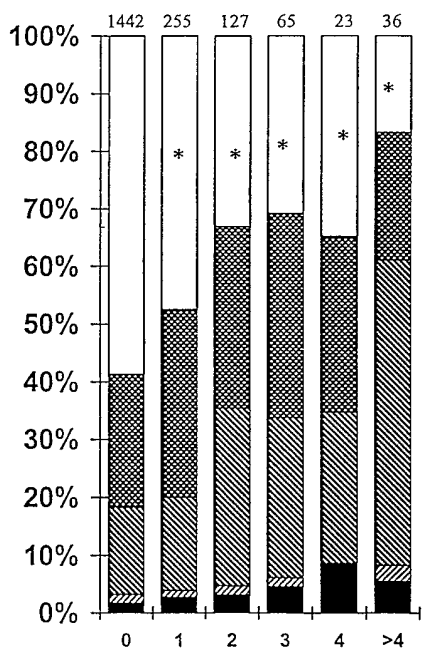

Fig. 2. Retinopathy at 6 years by number of microaneurysms at entry. Annotation as in Fig. 1

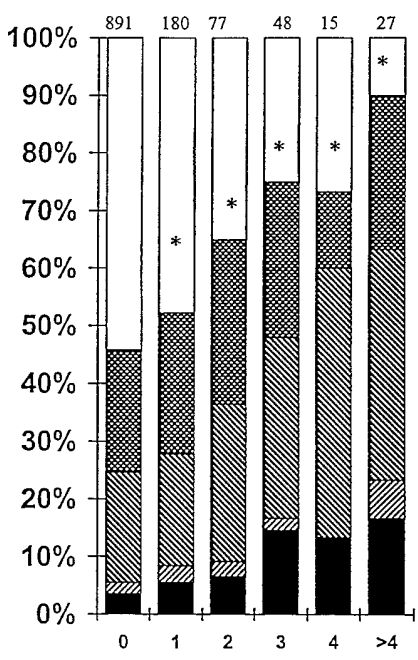

Fig. 3. Retinopathy at 9 years by number of microaneurysms at entry. Annotation as in Fig. 1

3 year and 6 years, whereas between 6 and 9 years $20.9 \%$ developed MA for the first time. Table 4 summarises data on risk of retinopathy for patients without MAs at entry who had photos at 3, 6 and 9 years.

Progression of retinopathy. The progression of retinopathy is shown in Figs. 1-4. These show a pronounced almost linear increase of more severe forms of retinopathy with increasing number of MAs at entry and a concomitant decrease of those without retinopathy. The trend for this was highly statistically significant; at 6 years chi squared was $75,1 \mathrm{df}$, $p<0.0000001$, at 9 years chi squared was $61,1 \mathrm{df}$, $p<0.0001$ and at 12 years chi squared was $4.8,1 \mathrm{df}$, $p=0.029$.

To determine whether it was the duration of diabetes or the number of MAs which was indicative of retinopathy progression patients who had no retinop- 
Table 4. Cohort of 508 subjects with no MA at entry with photographs at each of 3,6 and 9 years

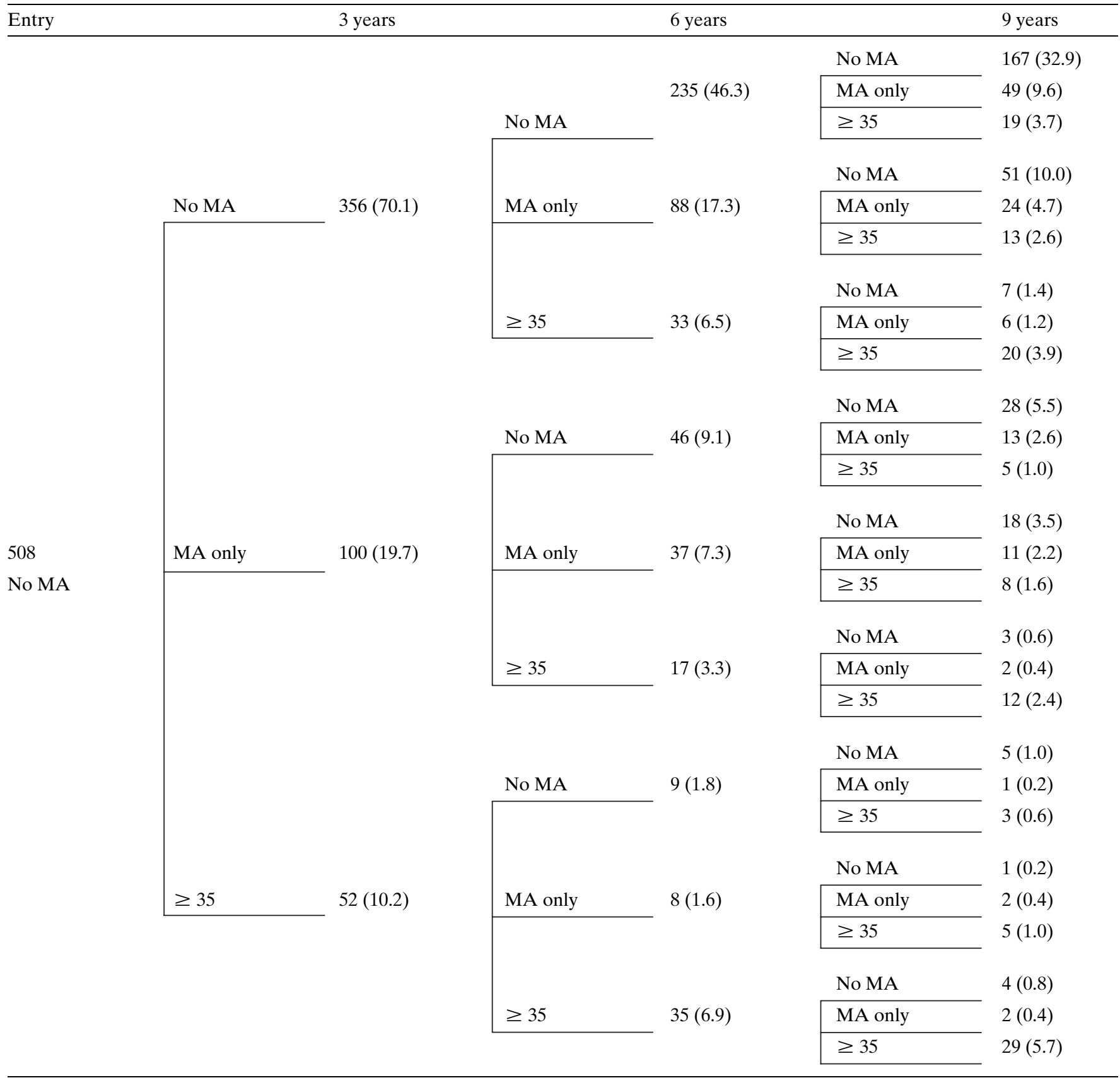

athy or MAs only at 3 years had their progression evaluated at 9 years (i.e. 6 years later, to make it comparable to the study between entry and 6 years). There was a similar almost linear increase in the development of more severe retinopathy with an increasing number of MAs, the trend using chi squared being 52,1 df, $p<0.0000001$ (Fig. 5). Indeed there is no statistically significant difference between Fig. 2 and 5 .

\section{Discussion}

This study shows that MAs are important predictive lesions for progression of diabetic retinopathy. There was an almost linear increase of severity of retinopathy and attainment of the end points of vitreous haemorrhage or photocoagulation with increasing number of the aneurysms and increasing duration of follow up. It might be expected that with longer duration of diabetes more severe lesions would be noted but comparing the progression between entry and 6 years with that of 3 to 9 years, the increase in retinopathy is very similar. The number of patients devel- 


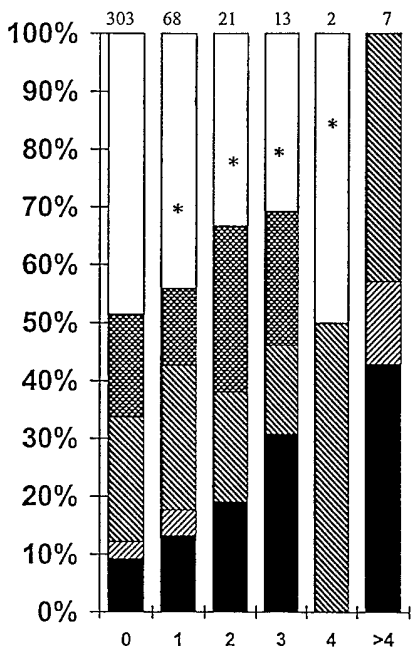

Fig. 4. Retinopathy at 12 years by number of microaneurysms at entry. Annotation as in Fig. 1

oping MAs for the first time was also similar at the 3 year intervals.

In this predictive value of the number of MAs for worsening retinopathy our findings are not dissimilar from the Wisconsin study [7,8]. At the 4 year examination in Wisconsin it was noted that those with 4 or more aneurysms had a statistically significantly increased trend to develop level 41 of the Wisconsin grading system [5] a level which indicated propensity to develop sight threatening retinopathy. Patients who increased their MA number and in whom the ratio of 4 year to entry MA number was highest were most likely to develop proliferative retinopathy and clinically significant macular oedema at 10 years. This was most pronounced in those who increased their MA number by 16 or more by 4 years. (The present study truncated counting before this number).

In our study at 6 years of patients with 2-4 MAs over $27 \%$ developed more severe non-proliferative retinopathy, (level $35<35$ or $35 / 35$ ) and up to $4.6 \%$ reached the end point of vitreous haemorrhage or photocoagulation. In those with 5 or more MAs, nearly $53 \%$ progressed to retinopathy, $2.8 \%$ reached moderate to severe non-proliferative retinopathy (level $43<43$ and worse) and $5.6 \%$ had photocoagulation or vitreous haemorrhage. Similarly, of the 22 patients who had 5 or more MAs at 3 years 11 or $50 \%$ deteriorated to level $35<35$ or $35 / 35$ and $2(9.1 \%)$ reached level 43 in at least 1 eye. Much larger numbers of MAs were counted in the Wisconsin study, [7,8] but they used 7 standard field stereo pair photographs and counted all MAs found and in our study the counting was less detailed. Also all of the patients in that study were among the younger patients with onset of Type I (insulin-dependent) diabetes mellitus and many had diabetes for many years before entering the study.

The large number of patients who had MAs at entering the study could be explained by the possibility

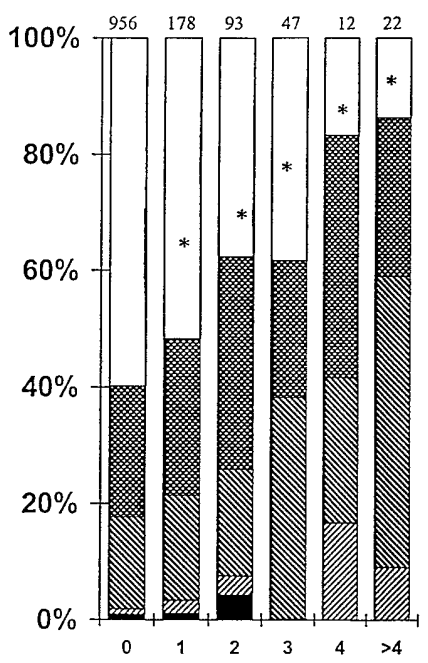

Fig.5. Retinopathy at 9 years by number of microaneurysms at 3 years. Annotation as in Fig. 1

that these patients had undiagnosed diabetes for some years before diagnosis. In a study which combined Wisconsin and Australian population-based studies [7] it was estimated that patients who have retinopathy at the time of diabetes diagnosis had the disease for between 4 and 7 years. The finding that about $20 \%$ of those without retinopathy at diagnosis in this study developed at least MAs by 6 years suggest that these patients were more similar to the Wisconsin than the Australian patients. The steady $20 \%$ developing MAs if they had no retinopathy 3 years previously could support the finding that the formation rate of MAs is independent of blood glucose control and other medical variables [7] and these factors only affect the more severe forms of retinopathy. That patients with a greater number of MAs had a more rapid advance to more severe forms of retinopathy also suggests that these patients may have had a longer duration of undiagnosed diabetes [9].

To be noted from this study is that MAs are important lesions which predict the progression of retinopathy. The presence of even one or two MAs only should alert doctors of the importance of careful follow-up of these patients. Screening techniques which miss MAs, such as Polaroid and some digital photographs should be ideally repeated at yearly intervals if possibly sight threatening lesions are to be recognised early.

Acknowledgements. The study was conducted at the following centres in the United Kingdom: Royal Infirmary, Aberdeen; City Hospital, Belfast; Royal Victoria Hospital, Belfast; General Hospital, Birmingham; St. Helier Hospital, Carshalton; Derbyshire Royal Hospital, Derby; Ninewells Hospital, Dundee; Royal Devon and Exeter Hospital, Exeter; Ipswich Hospital, Ipswich; Leicester General Hospital, Leicester; St. George's Hospital, London; Hammersmith Hospital, London; Whittington Hospital, London; Royal Infirmary, Manchester; Norfolk and Norwich Hospital, Norwich; Northampton Gen- 
eral Hospital, Northampton; Radcliffe Infirmary, Oxford; Peterborough Hospital, Peterborough; Hope Hospital, Salford; Lister Hospital, Stevenage; North Staffordshire Royal Infirmary, Stoke-on-Trent; Torbay Hospital, Torbay.

The co-operation of the patients and many National Health Service and Non-National Health Service staff at all the centres is much appreciated.

Funding was provided by: National Eye Institute 2 UO1 EY07049-09, Bethesda, Maryland, USA; British Diabetic Association; Medical Research Council; National Institutes of Digestive Disorders and Kidney Disease NIH, Bethesda, Maryland, USA; UK Department of Health; British Heart Foundation and from pharmaceutical companies including: Bayer, Bristol Myers Squibb, Hoechst, Lilly, Novo Nordisk, Lipha and Farmitalia Carlo Erba and from additional companies including Securicor, Kodak and Cortecs Diagnostics.

\section{References}

1. Hiller R, Sperduto R, Podgor M, Ferris 3rd F, Wilson PW (1988) Diabetic retinopathy and cardiovascular disease in type II diabetics. The Framingham Heart Study and Framingham Eye Study. Am J Epidemiol 128: 402-409

2. UKPDS Group (1991) UK Prospective Diabetes Study VIII: study design, progress and performance. Diabetologia 34: 877-890
3. UKPDS Group (1995) UK Prospective Diabetes Study 13: Relative efficacy of randomly allocated diet, sulphonylurea, insulin, or metformin in patients with newly diagnosed non-insulin dependent diabetes followed for three years. BMJ 310: 83-88

4. UKPDS Group (1997) UK Prospective Diabetes Study 30: diabetic retinopathy at diagnosis of type 2 diabetes and associated risk factors. Arch Ophthalmol 116: 297-303

5. Klein B, David M, Segal P (1998) Diabetic Retinopathy at diagnosis of non-insulin depenedent diabetes and associated risk factors. Arch Ophthalmol 116: 297-303

6. Early Treatment Diabetic Retinopathy Study Research Group (1991) Grading diabetic retinopathy from steriopscopic color fundus photographs - an extension of the modified Airlie House classification. ETDRS Report No 10. Ophthalmology 98: 768-806

7. Klein R, Meuer S, Moss S, Klein B (1995) Retinal microaneurysm counts and 10 year progression of diabetic retinopathy. Arch Ophthalmol 113: 1386-1392

8. Klein R, Meuer S, Moss S, Klein B (1989) The relationship of retinal microaneurysm counts to the 4 year progression of diabetic retinopathy. Arch Ophthalmol 107: 1780-1785

9. Harris M, Klein R, Welborn T, Knuiman M (1992) Onset of NIDDM occurs at least 4-7 years before clinical diabetes. Diabetes Care 15: 815-819 